\title{
Preface from ERS President 2018 Mina Gaga and ERS Early- Career Member Committee Chair Lieuwe Bos
}

The ERS International Congress is one of the biggest annual events in the respiratory calendar-bringing over 20,000 respiratory professionals together for the latest scientific knowledge and hot topics in respiratory medicine.

Our Congress is an inclusive event; the programme has something for everyone, whether you are a clinician, a scientist or allied health professional, whether you are in the early stages of your career or a professional with many years' experience.

We appreciate that there are many people who would have liked to attend the Congress who were unable to make it, and are pleased to present reviews and highlights from the 2017 ERS Congress programme, which featured high-standard sessions and symposia touching on the major fields and developments in respiratory science—all expertly delivered by worldleaders in each field.

This year, we were extremely pleased to offer two joint Chinese sessions in collaboration with the Chinese Thoracic Society (CTS), and the reviews from those sessions are amongst the contributions we have included in this publication. The sessions were attended not only by attendees present in Milano but also by attendees in three hubs in China, where the sessions were broadcasted live on-line and questions could be asked from all these hubs as well as from the auditorium.

This issue of the journal has not only reviews from those presentations but also reports from our assemblies, summarizing selected new data that were presented at this 2017 ERS annual congress in each field. The reports are prepared with the participation and editorship of our Early Career Member Committee (ECM Committee).

The ECM Committee represents all our up to 40 years of age members. This Committee ensures the active participation of early career members of our Society into all out activities. And this is a particular aim and wish of our Society: we specifically wish to support our younger members in their research, education and career development. We want to help them network with their peers and with our senior clinicians and investigators, to blend into our networking and long-term plans. They are the future of our Society and our future leadership. So, this issue of the journal features reports prepared by the ECM committee, in collaboration with our Assembly Secretaries and we hope you will enjoy them.

In addition to the reviews featured here, we also invite you to visit the ERS website to access presentations from the sessions once they are made available. Furthermore, for a fee, our Live@ERS Plus service offers you an opportunity to watch sessions from Congress online up to 3 months after the event has taken place.

We do hope that you can join us in Paris, where we will host the ERS International Congress 2018, but in the meantime, we wish you pleasant reading.

\section{Acknowledgements}

None.

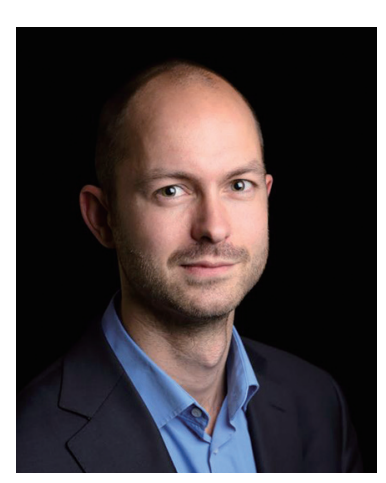

Lieuwe D. J. Bos

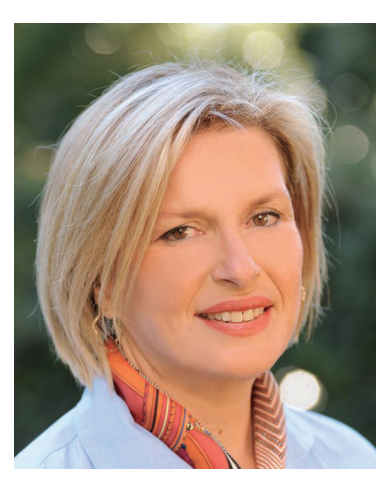

Mina Gaga 
Mina Gaga, MD, PhD

7th Respiratory Medicine Department and Asthma Centre, Athens Chest Hospital, Athens, Greece. (Email: minagaga@yahoo.com)

Lieuwe D. J. Bos, MD, PhD

Respiratory Medicine and Intensive Care at the Academic Medical Center, University of Amsterdam, Amsterdam, the Netherlands.

(Email: l.d.bos@amc.uva.nl) doi: $10.21037 /$ jtd.2017.11.38

Conflicts of Interest: The authors have no conflicts of interest to declare. View this article at: http://dx.doi.org/10.21037/jtd.2017.11.38

Cite this article as: Gaga M, Bos L. Preface from ERS President 2018 Mina Gaga and ERS Early-Career Member Committee Chair Lieuwe Bos. J Thorac Dis 2017;9(Suppl 16):S1524-S1525. doi: $10.21037 /$ jtd.2017.11.38 